\title{
AGO HITS-CLIP reveals distinct miRNA regulation of white and brown adipose tissue identity
}

\author{
Sean O'Connor, ${ }^{1,5}$ Elisabeth A. Murphy, ${ }^{2,5}$ Sarah K. Szwed, ${ }^{1,3}$ Matt Kanke, ${ }^{4}$ François Marchildon, ${ }^{1}$ \\ Praveen Sethupathy, ${ }^{4}$ Robert B. Darnell, ${ }^{2}$ and Paul Cohen ${ }^{1}$ \\ ${ }^{1}$ Laboratory of Molecular Metabolism, The Rockefeller University, New York, New York 10065, USA; ${ }^{2}$ Laboratory of Molecular \\ Neuro-Oncology, The Rockefeller University, New York, New York 10065, USA; ${ }^{3}$ Weill-Cornell/Rockefeller/Sloan Kettering Tri- \\ Institutional MD-PhD Program, New York, New York 10065, USA; ${ }^{4}$ Department of Biomedical Sciences, Cornell University, \\ Ithaca, New York 14853, USA
}

\begin{abstract}
MicroRNAs (miRNAs) are short, noncoding RNAs that associate with Argonaute (AGO) to influence mRNA stability and translation, thereby regulating cellular determination and phenotype. While several individual miRNAs have been shown to control adipocyte function, including energy storage in white fat and energy dissipation in brown fat, a comprehensive analysis of miRNA activity in these tissues has not been performed. We used high-throughput sequencing of RNA isolated by cross-linking immunoprecipitation (HITS-CLIP) to comprehensively characterize the network of high-confidence, in vivo mRNA:miRNA interactions across white and brown fat, revealing >20,000 unique AGO binding sites. When coupled with miRNA and mRNA sequencing, we found an inverse correlation between depot-enriched miRNAs and their targets. To illustrate the functionality of our HITSCLIP data set in identifying specific miRNA:mRNA interactions, we show that miR-29 is a novel regulator of leptin, an adipocyte-derived hormone that coordinates food intake and energy homeostasis. Two independent miR-29 binding sites in the leptin $3^{\prime}$ UTR were validated using luciferase assays, and miR-29 gain and loss of function modulated leptin mRNA and protein secretion in primary adipocytes. This work represents the only experimentally generated miRNA targetome in adipose tissue and identifies multiple regulatory pathways that may specify the unique identities of white and brown fat.
\end{abstract}

[Keywords: adipose; brown fat; HITS-CLIP; white fat; miRNA]

Supplemental material is available for this article.

Received October 11, 2020; revised version accepted March 1, 2021.

Worldwide obesity rates have nearly tripled over the last four decades, and in the U.S. nearly $50 \%$ of adults are projected to be obese by 2030 (Ward et al. 2019). Obesity is characterized by excess white adipose tissue (WAT), which accumulates in either subcutaneous or visceral depots. While visceral obesity is strongly associated with a constellation of chronic diseases, including type 2 diabetes, cardiovascular disease, nonalcoholic fatty liver disease, and certain cancers, subcutaneous obesity is generally less deleterious (Neeland et al. 2019; Jayedi et al. 2020).

Mammals also possess brown adipose tissue (BAT) (Rosen and Spiegelman 2014), which can dissipate energy via adaptive thermogenesis and may offset many of the

\footnotetext{
${ }^{5}$ These authors contributed equally to this work.

Corresponding author: pcohen@rockefeller.edu

Article published online ahead of print. Article and publication date are online at http://www.genesdev.org/cgi/doi/10.1101/gad.345447.120.
}

risks associated with visceral adiposity. In mice, transplantation of BAT decreases insulin resistance, improves glucose tolerance, and lowers total fat mass (Stanford et al. 2013). Adrenergic stimulation of BAT, such as by cold exposure, similarly improves glucose uptake, increases energy expenditure, and protects against diet-induced obesity in mice (Kajimura et al. 2015). Cold exposure additionally induces the activation of beige fat cells in subcutaneous WAT, which engage in thermogenesis and confer many of the same metabolic benefits as BAT (Wu et al. 2012). While BAT and beige fat may not be as abundant in humans, recent studies suggest these

(C) $2021 \mathrm{O}^{\prime}$ Connor et al. This article is distributed exclusively by Cold Spring Harbor Laboratory Press for the first six months after the full-issue publication date (see http://genesdev.cshlp.org/site/misc/terms.xhtml). After six months, it is available under a Creative Commons License (Attribution-NonCommercial 4.0 International), as described at http://creativecommons.org/licenses/by-nc/4.0/. 
thermogenically active fat cells can be activated in response to cold or other stimuli (Cypess et al. 2009; van Marken Lichtenbelt et al. 2009; Virtanen et al. 2009), presenting an opportunity for therapeutic intervention.

Much of the work on adipocyte differentiation and phenotype over the past few decades has focused on transcriptional regulators of cellular identity. These include Pparg2, which is both necessary and sufficient for the development and maintenance of white and brown adipocytes (Tontonoz et al. 1994; Tontonoz and Spiegelman 2008), and Prdm16, which regulates brown and beige adipocyte identity (Seale et al. 2007; Cohen et al. 2014). More recently, it has become clear that post-transcriptional regulators also play a key role in influencing adipocyte phenotype. Studies with adipose-specific dicer KO mice demonstrate that microRNAs (miRNAs) are essential in regulating adipogenesis, insulin sensitivity, and nonshivering thermogenesis (Mori et al. 2014; Reis et al. 2016). Several individual miRNAs have been shown to contribute to these phenotypes. For example, miR-133 represses BAT function by directly targeting Prdm16 and inhibiting expression of thermogenic genes (Trajkovski et al. 2012), miR-196a induces browning of WAT by targeting Hoxc8 (Mori et al. 2012), miR-155 regulates the differentiation of brown and beige adipocytes (Chen et al. 2013), and miR-26 protects from diet-induced obesity by blocking adipogenesis (Acharya et al. 2019). These studies, and most others in adipose tissue, rely on computational predictions and low-throughput validation to identify miRNA targets. Although high-throughput cross-linking techniques to map the miRNA targetome have been applied to liver, brain, heart, and other organs (Chi et al. 2009; Spengler et al. 2016; Luna et al. 2017), thus far, no comprehensive targetome has been reported for adipose tissue.

Here, we performed miRNA sequencing to comprehensively profile miRNA levels across adipose depots, followed by HITS-CLIP to characterize miRNA binding behavior in iBAT and eWAT. These data are complemented by RNA sequencing to assess the effects of miRNA binding on steady-state mRNA levels. Our data provide a rich resource of miRNA expression coupled with in vivo miRNA targeting behavior, which we used to characterize the role of miR-29 in suppressing leptin production. Moreover, these studies provide a wealth of data for future investigations of miRNA regulatory interactions in white and brown fat.

\section{Results}

\section{Global profiling of microRNAs across fat depots}

In order to broadly profile miRNAs across mouse adipose tissues, we sequenced small RNAs covering the full spectrum of adipocyte phenotype, ranging from white to brown fat. These included two visceral fat depots, epididymal WAT (eWAT) and mesenteric WAT (mWAT); two subcutaneous fat depots, inguinal WAT (iWAT) and axillary WAT (aWAT); and interscapular BAT (iBAT) (Fig. 1A; Supplemental Table S1). We first compared the four WAT depots with iBAT and identified dozens of WAT-enriched miRNAs in each depot (Supplemental Fig. S1A). Global clustering analysis of the top 100 expressed miRNAs identified depot-specific clusters, with a particularly distinct profile observed in iBAT (Fig 1B). By comparison, the two subcutaneous fat depots, which demonstrate the greatest plasticity and have a molecular phenotype intermediate from the visceral/BAT extremes (Wu et al. 2012; Rosenwald et al. 2013), cluster together and most closely match the mean miRNA expression profile (Fig. 1B).

Given that many of the regulatory mechanisms governing subcutaneous fat function may only be revealed following perturbation, we also sequenced small RNAs from iWAT of mice that had been cold-exposed (1 wk at $\left.4^{\circ} \mathrm{C}\right)$ to stimulate beige fat biogenesis (cWAT). There were significant changes in the abundance of several miRNAs in response to cold exposure, including an increase in let-7 and miR-30 and a decrease in miR-125 and miR-27 (Fig. 1C,D), all of which have been implicated in brown and beige adipocyte function (Fu et al. 2014; Sun and Trajkovski 2014; Giroud et al. 2016a,b) . To assess the effects of cold exposure on a global scale, we performed a principal component analysis (PCA) with all samples (Fig. 1E). Cold exposure did not significantly change the miRNA profile of iWAT along the first two principal components (Fig. 1E). In contrast, eWAT and iBAT samples clustered closely among biological replicates and diverged significantly along the first principal component, suggesting an important role for miRNAs in controlling phenotypic differences between these two types of adipose tissue. A volcano plot analysis shows that many of the miRNAs that differ most significantly between eWAT and iBAT have been shown to impact iBAT function or regulate adipocyte metabolism, including miR-30 ( Hu et al. 2015), miR-193b (Sun et al. 2011), miR-34 (Fu et al. 2014), and miR-107 (Trajkovski et al. 2011).

\section{Differential AGO regulation in iBAT and eWAT depots}

As eWAT and iBAT are the two most divergent types of adipose tissue, both by phenotype and miRNA expression profiles, we examined in vivo miRNA targeting in these two tissues. To capture a broad, unbiased map of miRNA:mRNA interactions, we performed HITS-CLIP to biochemically identify AGO/miRNA regulatory sites in mRNAs in a high-throughput manner. Following UV cross-linking, AGO:RNA complexes were immunoprecipitated (Supplemental Fig. S2A), radiolabeled, and separated by gel electrophoresis. iBAT and eWAT samples contained a range of RNA fragment lengths, illustrated by a dense smear on the autoradiograph, compared with IgG and noncross-linked controls (Supplemental Fig. S2B). After excising AGO:RNA complexes of $~ 110-170$ $\mathrm{kDa}$ and sequencing AGO-associated RNAs, iBAT and eWAT samples separated effectively by PCA (Fig. 2A) and showed low inter-sample variability by Pearson correlation (Supplemental Fig. S2C). mRNA tags (sequencing reads corresponding to AGO-associated mRNA fragments) were clustered into significant peaks, revealing a total of 20,697 unique peaks across 5248 genes, with 
A

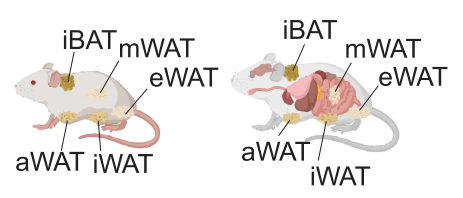

B

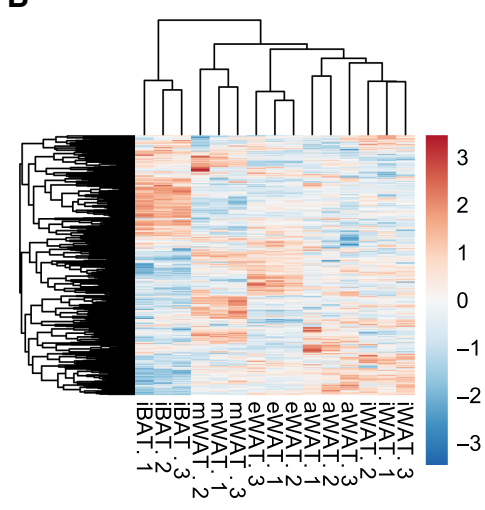

E

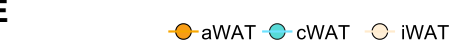

-O-iBAT -O-eWAT -O- mWAT

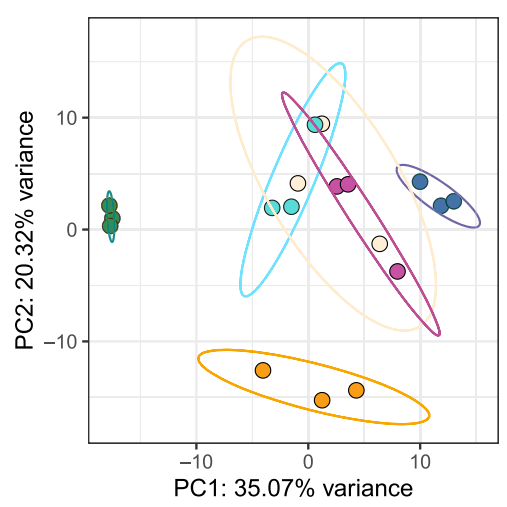

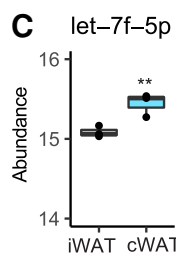
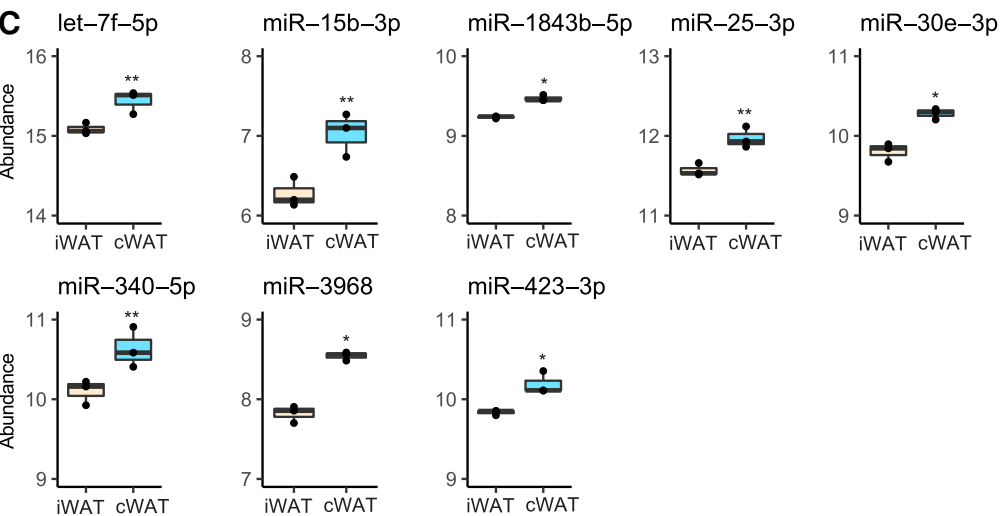

$$
\text { miR-423-3p }
$$
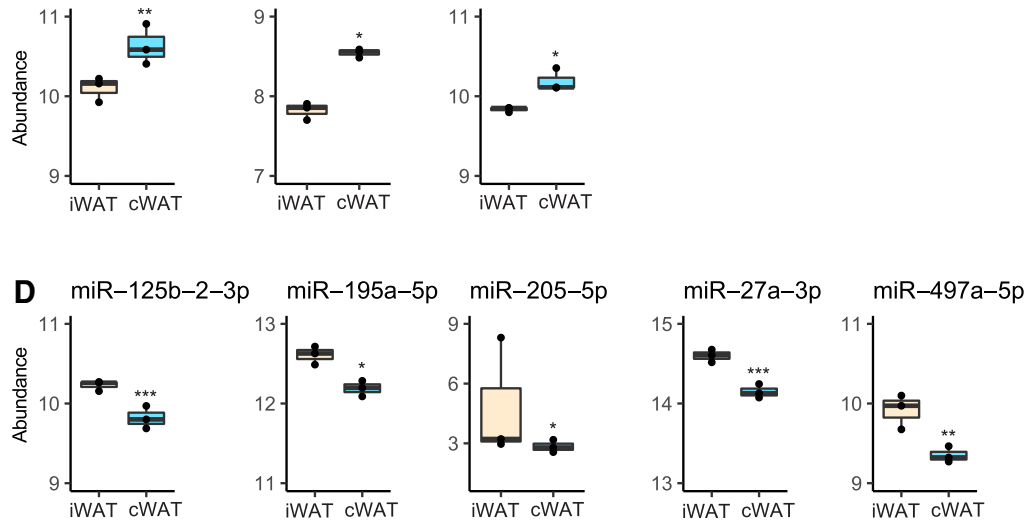

$\mathbf{F}$

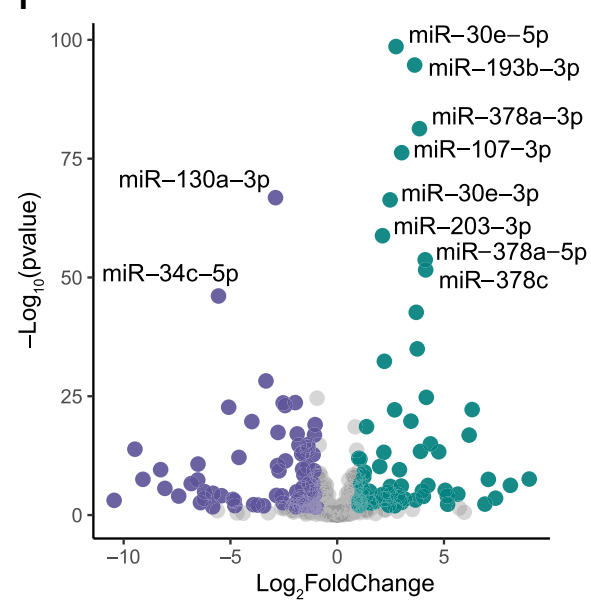

Figure 1. miRNA-seq identified divergent miRNA profiles in eWAT and iBAT depots. (A) Anatomical schematic of sampled adipose depots (left) and their locations relative to other organs (right) in the male mouse. (B) Global cluster analysis of miRNA-seq expression profile of the top 100 expressed miRNAs clustered by adipose depot from 13-wk-old male mice housed at room temperature (three mice pooled per group, $n=3$ biological replicates per depot). $(C, D)$ miRNAs with a significant increase $(C)$ or decrease $(D)$ in inguinal adipose tissue in response to cold exposure for $1 \mathrm{wk}$ at $4^{\circ} \mathrm{C}$ prior to sacrifice (cold-exposed WAT $=\mathrm{cWAT}$ ). Expressed as normalized miRNA abundance. $\left.\left(^{*}\right) P<0.05,{ }^{* *}\right) P<0.005,(* *) P<0.0005$. The black horizontal bar is the median, the box shows the 25 th-75th percentile, and whiskers show max and min. (E) Principal component analysis of miRNA expression profiles by adipose depots defined in $A$, including cWAT. Samples are color-coded based on depot. $(F)$ Volcano plot of significantly differentially expressed miRNAs (DESEQ2) between iBAT and eWAT. (Green) miRNAs enriched in iBAT relative to eWAT, (blue) miRNAs enriched in eWAT relative to iBAT. The most significantly differentially expressed miRNAs are highlighted.

14,562 unique iBAT peaks and 928 unique eWAT peaks, consistent with the greater number of iBAT unique RNA reads (Supplemental Table S2). A slightly higher percentage of iBAT-specific peaks (59\%) localized to $3^{\prime}$ untranslated regions (UTRs) than eWAT-specific peaks $(55 \%)$, and most of the remaining peaks localized to exons (Fig. 2B). Next, we identified enriched KEGG pathways among genes with increased AGO binding in iBAT and eWAT (Fig. 2C), revealing that several genes involved in thermogenesis, including Pparg and Pnpla2, show increased AGO binding in iBAT. miR-27, a known suppressor of beige fat function is among the miRNAs targeting an iBAT-specific peak in Pparg (Sun and Trajkovski 2014), while miR-182, a highly iBAT-enriched miRNA, targets an iBAT-specific peak in Pnpla2 (Supplemental Fig. 2 D,E; the complete set of miRNA seed-to-peak matches used for analysis in this study is in Supplemental Table S4 and is based on a valley depth of 0.9 for peak 

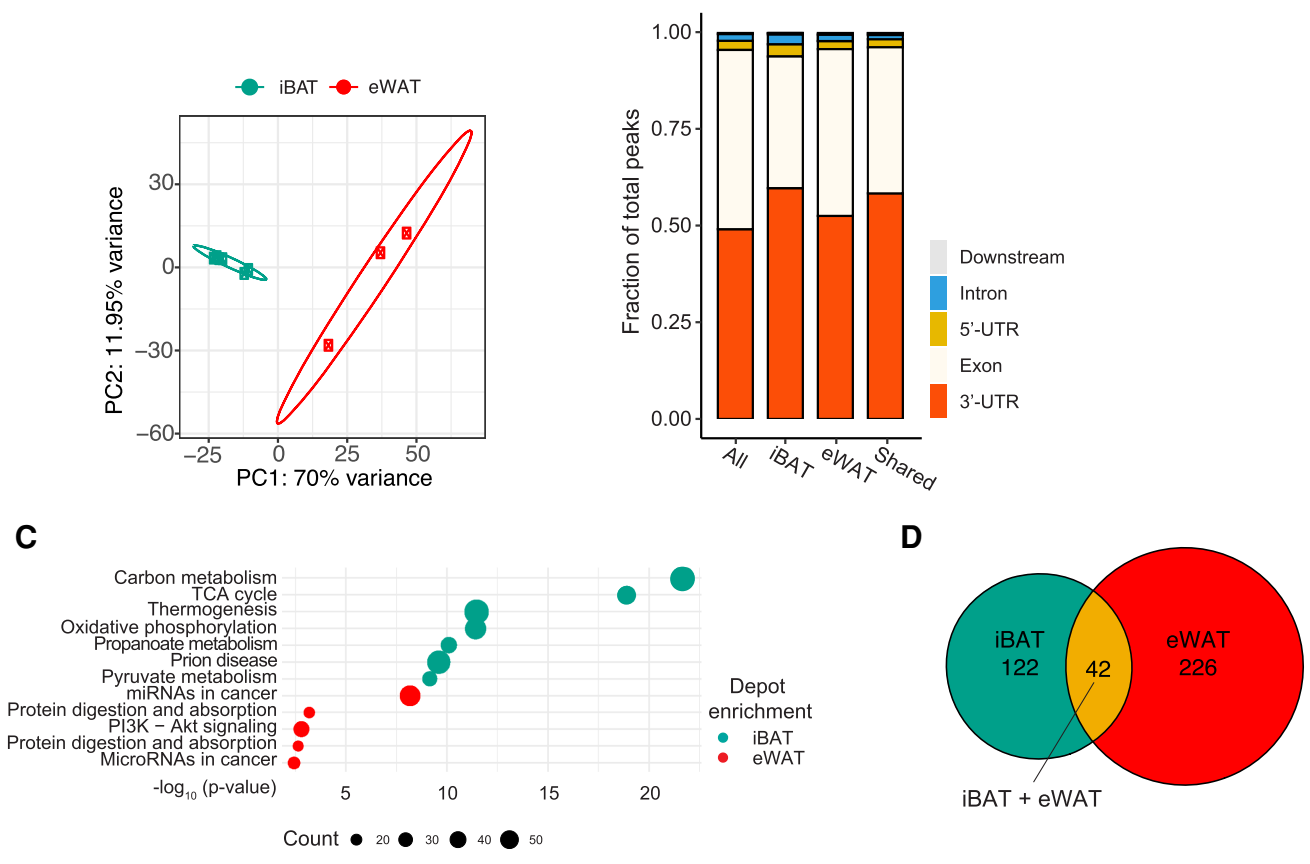

E

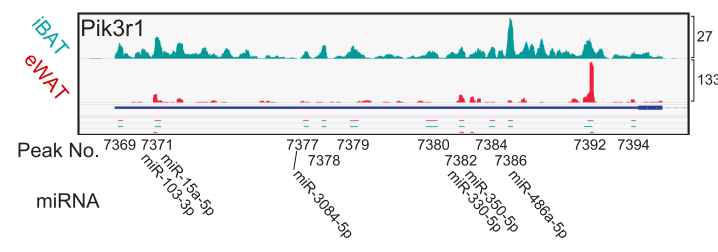

$\mathbf{F}$

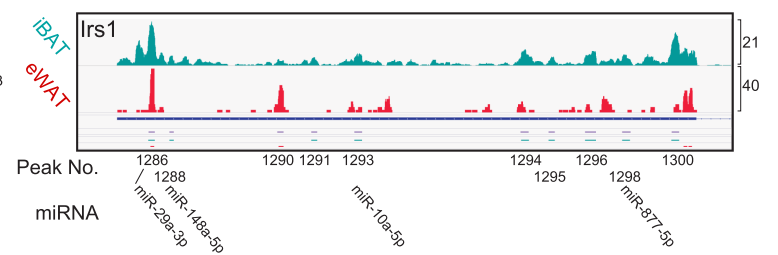

Figure 2. HITS-CLIP identifies differential AGO regulation in iBAT and eWAT depots. (A) PCA analysis of HITS-CLIP peaks from iBAT and eWAT (15-wk-old male mice, two mice pooled per group, $n=6$ groups for BAT, $n=3$ groups for eWAT). (B) Genomic location of depotspecific HITS-CLIP peak distribution by annotated region and depot, expressed as fraction of total peaks. (Shared) Peak is significant in both iBAT and eWAT, (all) peak is significant when iBAT and eWAT reads are pooled before scanning for peaks. $(C)$ KEGG gene set enrichment analysis of genes with iBAT- and eWAT-specific peaks (significant differential peak defined as $\left|\log _{2} \mathrm{FC}\right|>1$ and $P$ adj $\left.<0.05\right)$. $(D)$ Venn diagram depicting differential peak usage across depots. One-hundred-twenty-two genes contained iBAT-specific but no eWAT-specific peaks, 226 genes contained eWAT-specific but no iBAT-specific peaks, and 42 genes contained both iBAT- and eWAT-specific peaks. $(E, F)$ Gene tracks of miRNA-dependent differentially regulated targets Pik3r1 $(E)$ and $\operatorname{Irs} 1(F)$ showing $3^{\prime}$ UTR-localized HITS-CLIP tags. (Purple) Significant peaks called from aggregated reads, (red) significant peaks called from eWAT reads only, (teal) significant peaks called from iBAT reads only. Scale for each gene track was normalized by the tallest peak.

disaggregation; as an additional resource, Supplemental Table S5 shows a less stringent analysis using a valley depth of 0.5 ).

Next, to identify peaks with depot-specific regulation while accounting for differences in total AGO binding, peaks enriched in iBAT or eWAT were subsetted from genes with equal levels of total tags, resulting in 226 genes with eWAT-specific peaks, 122 genes with iBAT-specific peaks, and 42 genes with both iBAT- and eWAT-specific peaks (Fig. 2D; Supplemental Table S3). Among these were several genes known to influence adipocyte metabolism, including Pik3r1 (Fig. 2E) and Irs1 (Fig. 2F), both of which are involved in insulin signal transduction. Interestingly, miR-10b-5p is a highly expressed eWAT-enriched miRNA that binds to peak 1293 in Irs1, suggesting a potential role in promoting insulin resistance in visceral fat.
CLIP peak-score elucidates AGO-driven changes in RNA steady-state levels across $\mathrm{iBAT}$ and eWAT depots

AGO regulation is just one way in which a cell can control gene expression in the setting of a dynamically changing transcriptional profile. To account for changes in the transcriptome, we normalized CLIP tags for transcript abundance, allowing AGO targets to be ranked by relative binding. We first performed RNA sequencing of eWAT and iBAT to measure transcript abundance for each depot. Next, we calculated a "CLIP score" to define AGO binding affinity at each peak site based on both cross-linked events determined via CLIP and transcript abundance determined via RNA-seq, as described previously (Sawicka et al. 2019). We summarized CLIP tag density for each peak (per replicate) and correlated it with transcript 
abundance (Supplemental Fig. S3A). We then used this to generate a "CLIP peak score" for each binding site, which quantifies AGO binding relative to all other transcripts of comparable abundance (Supplemental Table S3). For each CLIP replicate, a linear regression was fitted through a plot of CLIP tags versus RNA-seq tags per million (TPMs), and the position of each peak was determined relative to the fitted line. For a given peak, the greater the distance above the regression line, the higher the CLIP peak score and the greater the inferred AGO binding.

Our study aims to characterize differential AGO regulation across iBAT and eWAT depots. Therefore, we asked how changes in AGO binding compare with changes in mRNA abundance across these two depots. When we examined the relationship between CLIP peak score and mRNA abundance, we found that many of the high affinity iBAT binding sites are in genes that are more highly expressed in iBAT relative to eWAT (Fig. 3A, quadrant I). Likewise, a portion of high-affinity eWAT binding sites are localized to mRNAs that are more highly expressed in eWAT relative to iBAT (Fig. 3A, quadrant III). These represent depot-specific AGO binding sites likely linked with transcriptional regulation. In addition to identifying AGOregulated peaks with depot-specificity, we identified a
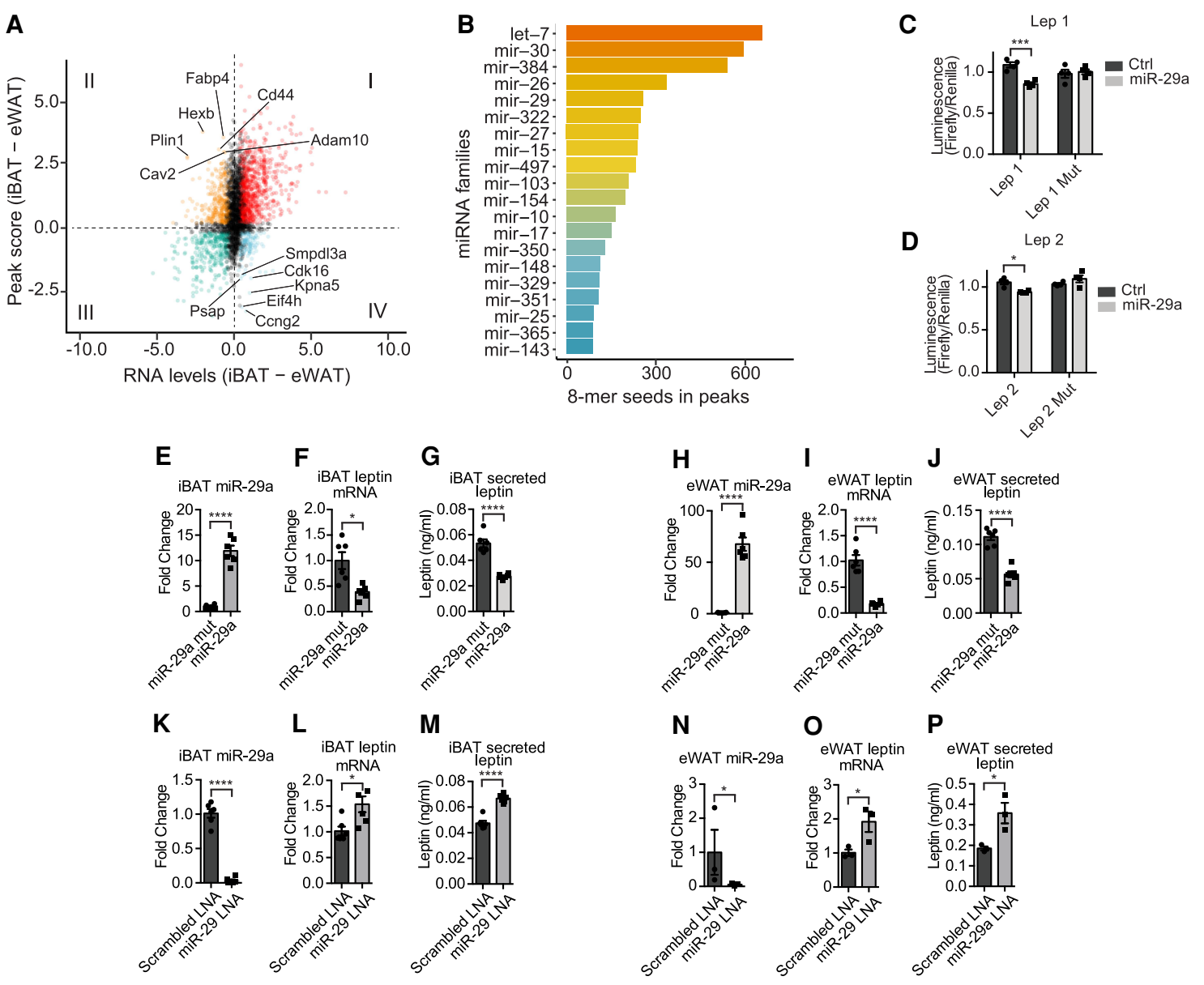

J
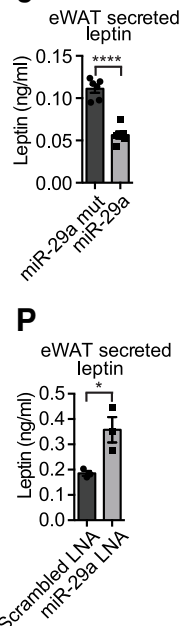

Figure 3. CLIP peak score for predicting AGO-driven changes in RNA steady-state levels. (A) Difference in mRNA abundance (iBATeWAT mRNA) plotted against difference in CLIP peak score (iBAT-eWAT) for AGO-binding sites. (Quadrant I) mRNA enriched in iBAT and a higher iBAT CLIP score than eWAT. (Quadrant II) mRNA enriched in eWAT and a higher iBAT CLIP score than eWAT. (Quadrant III) mRNA enriched in eWAT and a higher eWAT CLIP score than iBAT. (Quadrant IV) mRNA enriched in iBAT and a higher eWAT CLIP score than iBAT. $(B)$ Bar plot of the top 20 miRNA families with 8-mer miRNA seed-matched sites in Ago peaks. (C,D) Dual-luciferase assay validation conducted by cotransfecting HEK-293A cells with plasmid containing luciferase enzymes and either a scrambled control miRNA or miR-29a. (Mut) Luciferase plasmid containing point mutations in seed sequence binding site. Lep 1 and Lep 2 refer to the miR-29 binding sites in leptin. Luciferase/renilla luminescence was normalized to scrambled control transfected cells and is presented as a fold change $(n=4)$. $(E-G)$ iBAT miR-29a, leptin mRNA, and conditioned media $(C M)$ leptin concentration from primary adipocyte cultures transfected with a miR-29a mimic or a mutated miR-29 mimic $(n=6)$. $(H-J)$ eWAT miR-29a, leptin mRNA, and conditioned media (CM) leptin concentration from primary adipocyte cultures transfected with a miR-29a mimic or a mutated miR-29 mimic $(n=$ 6). $(K-M)$ iBAT miR-29a, leptin mRNA, and CM leptin concentration in primary adipocyte cultures transfected with a miR-29 LNA or a scrambled LNA $(n=6)$. $(N-P)$ eWAT miR-29a, leptin mRNA, and CM leptin concentration in primary adipocyte cultures transfected with a miR-29 LNA or a scrambled LNA $(n=3)$. Results for $C-P$ are presented as mean \pm SEM. Two-way ANOVA was used for miR-29a to control comparisons in $C$ and $D$ and Student's $t$-tests were used for comparisons in $E-P .\left(^{*}\right) P<0.05,\left(^{* * *}\right) P<0.0005,\left({ }^{* * * *}\right) P<0.00005$. 
subset of regulatory sites that display an increase in AGO affinity in eWAT despite higher mRNA levels in iBAT (Fig. $3 \mathrm{~A}$, quadrant IV), as well as peaks with an increase in AGO affinity in iBAT despite higher mRNA levels in eWAT (Fig. 3A, quadrant II; Supplemental Table S3).

To demonstrate the utility of our HITS-CLIP data set in exploring specific miRNA:mRNA interactions, we first identified miRNAs most responsible for regulating gene expression in adipose tissue by ranking candidates by high-confidence seed matches (8-mer binding sites within the top 1000 peaks) (Fig. 3B). Many of the top ranked candidates have been thoroughly studied in adipocytes, including let-7 and miR-30 (Ventayol et al. 2014; Hu et al. 2015; Giroud et al. 2016a; Koh et al. 2018). For this reason, we focused on miR-29, an abundantly expressed miRNA that has been described previously as a regulator of the glucocorticoid receptor (GR) in adipocytes (Glantschnig et al. 2019) but has otherwise not been well studied in fat cells (our data show a miR-29 binding site in the iBAT GR, but not eWAT). Among miR-29's top binding sites, as ranked by peak score, was a peak localized to the leptin 3' UTR (Supplemental Table S4). Additionally, a second sequence complementary to the miR-29 seed was identified in the leptin $3^{\prime}$ UTR, distal to the first. To validate these sites, miR-29a mimics were cotransfected into HEK293A cells with a dual luciferase plasmid containing miRNA binding sites cloned into the $3^{\prime}$ UTR of firefly luciferase. Normalized luminescence was significantly decreased with miR-29a, but not a scrambled control, and mutations introduced specifically within the miR-29-3p seed sequence binding sites were sufficient to block this effect (Fig. 3C,D).

To assess the function of these binding sites, we transfected primary adipocytes with a miR-29a mimic. Seventy-two hours post-transfection, miR-29a-3p levels were substantially increased in both brown and white adipocytes (Fig. 3E,H). Leptin mRNA levels correspondingly decreased by $40 \%$ in brown adipocytes $(P=0.0054)$ and $80 \%$ in white adipocytes $(P<0.00001)$, relative to cells transfected with a mutated miR-29a mimic (Fig. 3F,I). Leptin secretion from primary adipocytes was lower than that from adipocytes in vivo; however, the conditioned media (CM) of primary fat cells contained a sufficient amount of leptin to be detected by ELISA. We observed a $50 \%$ decrease in leptin protein in CM from both brown and white adipocytes (Fig. 3G,J). As an alternative gain-of-function approach, primary cells were transduced with an adenovirus expressing miR-29a or a scrambled miRNA control. Consistent with the miRNA mimic experiments, an increase in miR-29a caused a 50\%-60\% decrease in leptin mRNA (Supplemental Fig. S3B,E). Next, primary cells were transfected with a locked nucleic acid (LNA) to knock down endogenous miR-29a-3p. Both primary iBAT and eWAT adipocytes showed a significant decrease in miR-29a-3p levels (Fig. 3K,N) and corresponding increases in leptin mRNA of $55 \%(P=0.015)$ and $90 \%(P=$ 0.044), respectively (Fig. 3L,O). In CM from both brown and white adipocytes, secreted leptin protein significantly increased in parallel with leptin mRNA (Fig. 3M,P). For each experiment, RNA levels of the general adipocyte dif- ferentiation markers Pparg2, Adipoq, and Ap2 were measured. The expression of these differentiation-dependent genes was modestly increased in adipocytes transfected with miRNA mimics (Supplemental Fig. S3F,G), consistent with previous reports that miR-29 promotes adipogenesis in human cells (Zhang et al. 2016). Importantly, leptin levels decreased in mimic-transfected cells despite the increase in markers of differentiation. Adenoviral gain-of-function and LNA-based loss of function did not alter markers of adipocyte differentiation (Supplemental Fig. $\mathrm{S} 3 \mathrm{H}-\mathrm{K})$.

In obese mice and humans, leptin mRNA and circulating protein are generally increased compared with lean controls, in proportion to body fat mass (Frederich et al. 1995; Maffei et al. 1995). We hypothesized that miR-29 levels would be inversely correlated with adiposity in models of obesity. Mice fed a HFD for 15 wk were $60 \%$ heavier than chow-fed controls (Fig. 4A) and had a fourfold increase in leptin mRNA in iBAT (basal levels of leptin in iBAT are very low), a 12-fold increase in eWAT, and an eightfold increase in serum leptin (Fig. 4B,C). miR-29a-3p levels were correspondingly reduced by $\sim 30 \%$ in iBAT $(P=0.027)$ and $60 \%$ in eWAT $(P<0.00001)$ (Fig. 4D). To confirm our findings, we next measured miR-29a abundance in a genetic model of obesity. Ob/ob mice were hyperphagic and obese relative to littermate controls (Fig. 4E) due to a nonsense mutation in the leptin coding sequence that led to high levels of leptin mRNA, but no functional protein (Fig. 4F,G). miR-29a in iBAT and eWAT of these mice was reduced by $24 \%(P=0.017)$ and $31 \%(P=$ 0.011 ), respectively (Fig. $4 \mathrm{H})$. We also considered the possibility that circulating leptin levels might regulate miR-29a expression. To that end, 60 -d-old $o b / o b$ mice were treated with recombinant leptin ( $300 \mathrm{ng} / \mathrm{h}$ via osmotic minipump) for $2 \mathrm{~d}$. To control for leptin's effects on food intake, a group of $o b / o b$ mice was treated with PBS and pair-fed to the leptin-treated group. After $2 \mathrm{~d}$, both groups of animals lost a comparable amount of weight (Supplemental Fig. S4A,B). We found no significant change in miR-29a abundance between these groups in iBAT or eWAT (Fig. 4I,J).

Human miR-29a-3p is identical in sequence to murine miR-29a-3p, and human leptin contains two TargetScanpredicted binding sites (Agarwal et al. 2015) that are moderately well conserved with those in mice (Fig. 4K). If miR$29 \mathrm{a}-3 \mathrm{p}$ serves as a physiologically relevant regulator of leptin in humans, our findings suggest that miR-29a-3p should be reduced in obese patients. Indeed, previously published work demonstrated that in a cohort of 66 men and women, ranging from lean to obese, miR-29a-3p in visceral and subcutaneous WAT is negatively correlated with BMI (Glantschnig et al. 2019). A second human study found an increase in miR-29a-3p in subcutaneous WAT from 19 obese individuals following diet- and exerciseinduced weight loss (Kristensen et al. 2017).

\section{Discussion}

In conclusion, we have conducted the first comprehensive biochemical mapping of miRNA:mRNA binding in white 

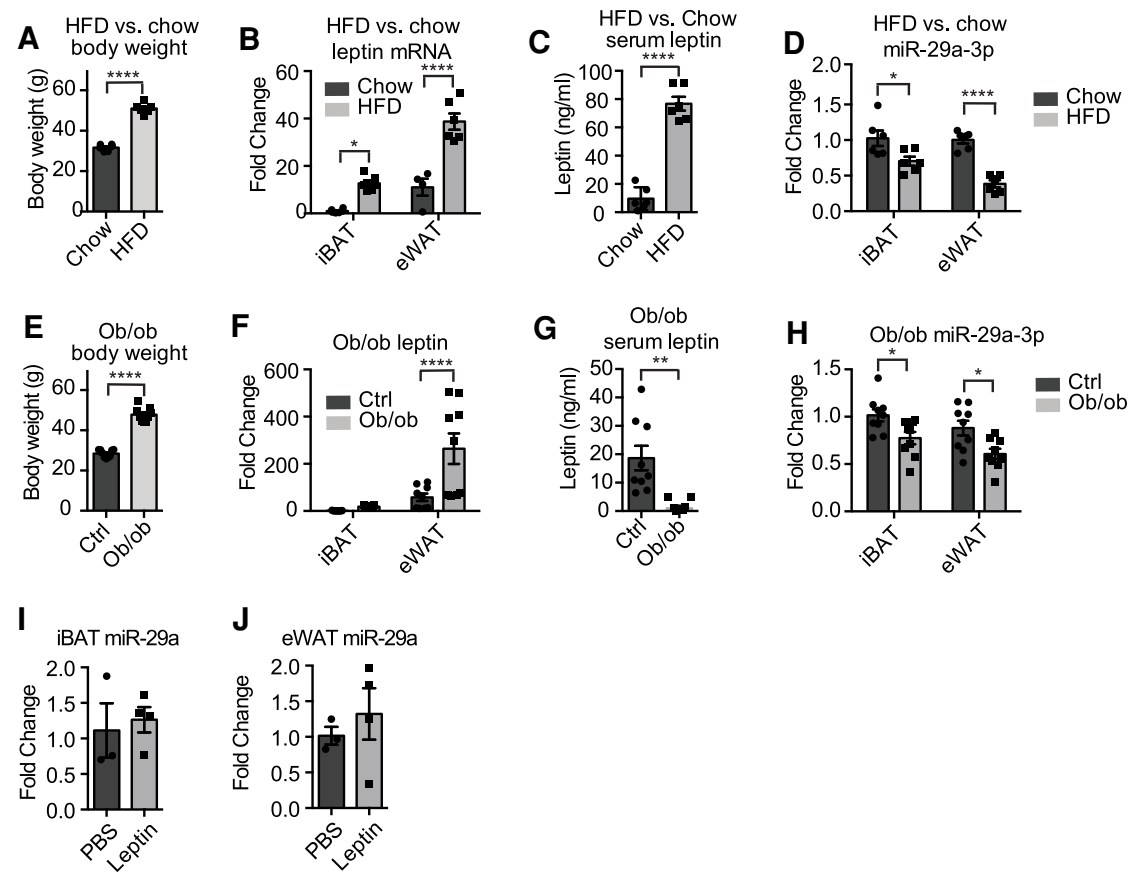

K

Lep 1

Hsa (1651-1658): TCATGCTCAGCCCTGACTGGTGCTATAGGCTGGAGAAGCTCA

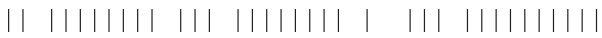

Mus (1473-1479): TCGTGCTCAGCTCTGTCTGGTGCTGTGAGCTAGAGAAGCTCA

Lep 2

Hsa (2335-2341): AGTTCTAGAGAAGAGGCTGGTGCTGTGGCCAGGGTGAGAGCT

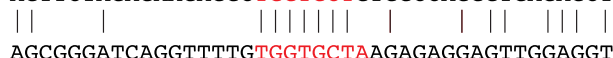

Mus (2204 - 2211): AGCGGGATCAGGTTTTGTGGTGCTAAGAGAGGAGTTGGAGGT
Figure 4. miR-29a and leptin levels are inversely correlated in obese mice. $(A-D)$, Twenty-one-week-old HFD versus chow mouse $(n=6)$ body weights $(A)$, leptin mRNA $(B)$, serum leptin $(C)$, and miR-29a levels $(D) .(E-H)$ Nine-week-old ob ${ }^{-/-}$versus $\mathrm{ob}^{+/-}$mouse $(n=9)$ body weights $(E)$, leptin mRNA $(F)$, serum leptin $(G)$, and miR29a levels $(H) .(I, J)$ miR-29a levels in iBAT $(I)$ and eWAT $(J)$ from $o b / o b$ mice treated with leptin or saline (PBS) and pair-fed to mice treated with recombinant leptin $(n=$ 3 for PBS treatment, $n=4$ for leptin treatment). (K) miR-29 binding seed sites (red) within the leptin $3^{\prime}$ UTR in mice and humans; the number in parentheses indicates location from start of the $3^{\prime}$ UTR. All results are presented as mean \pm SEM. Two-way ANOVA was used for leptin mRNA and miR-29a comparisons in $B, E, F$, and $H$ and Student's $t$-test was used for all other comparisons. $\left({ }^{*}\right) P<0.05,(* *) P<0.005,(* * *) P<$ $0.00005)$. and brown adipose tissue, providing an easily accessible resource for future studies. The stark phenotypic differences between iBAT and eWAT are mirrored by highly divergent miRNA expression profiles (Fig. 1E,F) and by AGO/miRNA regulatory behavior (Fig. 2C,D). iBAT-specific peaks indicate a role for miRNAs in controlling the citric acid cycle and thermogenesis, two pathways known to display significant heterogeneity across adipose depots (Rosen and Spiegelman 2014), suggesting that miRNAs may be important contributors to these phenotypic differences. Similarly, many eWAT-enriched peaks belong to the PI3K-Akt and insulin signaling pathways, consistent with eWAT being more prone to exhibiting insulin resistance (Hardy et al. 2012).

To further increase the utility of our data, we combined HITS-CLIP with mRNA-seq data to generate peak scores, which reflect AGO:mRNA affinity and allow for a ranking of miRNA targets (Fig. 3A). Comparisons between iBAT and eWAT revealed a number of peaks with peak scores that were the inverse of mRNA steady-state levels, indicative of depot-specific regulation (Fig. 3A). For example, our data show that Lpl, an eWATenriched gene that plays a central role in lipolysis, is more strongly bound by AGO in iBAT. In total, the 1079 peaks with inverse peak score/mRNA levels provide a rich source of previously unexplored, depot-specific interactions (Supplemental Table S3) that will serve as a valuable tool for future investigations into adipose tissue biology.

Finally, we focused our attention on the miR-29:leptin interaction to illustrate the functionality of the HITSCLIP data set. While lncRNAs have been shown to modulate leptin expression (Lo et al. 2018; Dallner et al. 2019), much of leptin's regulatory control remains unexplored. Our data describe miR-29 as a novel post-transcriptional regulator of leptin. These findings complement the previously described role of miR-29 in controlling mammalian metabolism, acting in the liver, heart, pancreas, and other organs (Pullen et al. 2011; Kurtz et al. 2015; Caravia et al. 2018). In addition to the leptin-miR-29 interaction, our data provide thousands of high-affinity miRNA: mRNA associations, demonstrating the power of HITSCLIP in identifying novel regulatory relationships in adipose tissue and providing a valuable resource for future discovery.

\section{Materials and methods}

Mouse experiments

Animal studies were performed according to procedures approved by the Institutional Animal Care and Use Committee at the Rockefeller University. Unless stated otherwise, all mice were males purchased from The Jackson Laboratory and on the C57BL/6 background, including ob/ob (stock no. 000632), WT 
(stock no. 000664), and high-fat diet (HFD)-fed mice (stock no. 380050). Controls for ob/ob mice were heterozygous littermates. Mice were group housed at five mice per cage (four for HFD) and maintained on 12-h light:dark cycles at $23^{\circ} \mathrm{C}$. HFD mice were fed a diet composed of $60 \%$ dietary fat (Research Diets D12492) from $6 \mathrm{wk}$ of age. All other animals were maintained on a chow diet, ad libitum. Mice chronically exposed to cold were individually housed at $4^{\circ} \mathrm{C}$ and closely monitored by laboratory personnel. For leptin experiments, 8.5 -wk ob/ob singly housed female mice were treated with recombinant leptin (R\&D 498OB05M) at $300 \mathrm{ng} / \mathrm{h}$ (ALZET osmotic minipump \#2002) for $2 \mathrm{~d}(n=4)$. The control group $(n=3)$ of ob/ob mice was treated with PBS and pair-fed to the leptin-treated group.

\section{CLIP sequencing}

iBAT and eWAT tissues were dissected from 15-wk-old male C57BL/6J mice and immediately flash-frozen in liquid nitrogen. Frozen iBAT and eWAT pairs were then pooled into groups of two, ground with a tissue pulverizer (Cellcrusher), and cooled in liquid nitrogen. Frozen samples were spread to a thin layer on Petri dishes precooled on dry ice and UV cross-linked three times at $400 \mathrm{~mJ} / \mathrm{cm}^{2}$ using a Stratalinker 2400 (Stratagene). All samples were stored at $-80^{\circ} \mathrm{C}$ until tissue lysis.

For each sample, $400 \mu \mathrm{L}$ of protein A Dynabeads (Invitrogen) was pooled, then prepared by washing three times with $1 \mathrm{~mL}$ of antibody binding (AB) buffer (AB; PBS, $0.02 \%$ Tween). Following the final wash, beads were resuspended in $400 \mu \mathrm{L}$ of $\mathrm{AB}$ per sample, $50 \mu \mathrm{L}$ of rabbit anti-mouse bridging antibody (Jackson ImmunoResearch 315005008) was added, and beads were rotated for $1 \mathrm{~h}$ at room temperature. Beads were then washed three times with 1 $\mathrm{mL}$ of $\mathrm{AB}$, resuspended in $\mathrm{AB}$, and incubated for $2 \mathrm{~h}$ at room temperature with either $12 \mu \mathrm{L}$ of pan-Ago antibody (clone A28) (Moore et al. 2014), or $12 \mu \mathrm{L}$ of mouse normal IgG (Santa Cruz Biotechnology sc-2343).

Tissue pellets were lysed with $800 \mu \mathrm{L}$ of lysis buffer (PXL[1× PBS, $0.1 \%$ SDS, $0.5 \%$ Na-DOC, $0.5 \%$ NP-40], RNase inhibitor [Promega N2615, one Complete EDTA-free protease inhibitor cocktail tablet [Roche 11873580001 ] per $10 \mathrm{~mL}$ ) and subjected to DNase treatment (24407355), using $30 \mu \mathrm{L}$ of DNase (Promega) and incubated by shaking at $1100 \mathrm{rpm}$ for $5 \mathrm{~min}$ at $37^{\circ} \mathrm{C}$. Samples were then centrifuged at $20,000 \mathrm{~g}$ for $20 \mathrm{~min}$, and a needle was used to withdraw $800 \mu \mathrm{L}$ of aqueous protein lysate while avoiding the lipid layer and pellet. Lysates were then treated with $20 \mathrm{U} / \mathrm{mL}$ RNase A (Affymetrix), first diluted to the indicated concentration by volume (e.g., 1:100 for "high RNase," or 1:10,000 for "low RNase $^{\prime \prime}$ ) in lysis buffer and then added at $8 \mu \mathrm{L} / \mathrm{mL}$ of lysate. Then samples were digested by shaking at $1100 \mathrm{rpm}$ for $5 \mathrm{~min}$ at $37^{\circ}$ C. Following RNase digestion, samples were added directly to prepared antibody-bound beads and rotated for $3 \mathrm{~h}$ at $4^{\circ} \mathrm{C}$.

After IP, the following washes were performed: twice with lysis buffer, twice with high-salt lysis buffer (5× PBS, 1\% Igepal, 0.5\% deoxycholate, $0.1 \%$ SDS), twice with stringent wash buffer (15 $\mathrm{mM}$ Tris at $\mathrm{pH} 7.5,5 \mathrm{mM}$ EDTA, $2.5 \mathrm{mM}$ EGTA, $1 \%$ Triton $\mathrm{X}$ $100,1 \% \mathrm{NaDOC}, 0.1 \%$ SDS, $120 \mathrm{mM} \mathrm{NaCl}, 25 \mathrm{mM} \mathrm{KCl}$ ), twice with high-salt wash buffer (15 mM Tris at $\mathrm{pH} 7.5,5 \mathrm{mM}$ EDTA, 2.5 mM EGTA, $1 \%$ Triton X-100, $1 \%$ NaDOC, $0.1 \%$ SDS, 1 M $\mathrm{NaCl})$, twice with low-salt wash buffer (15 mM Tris at $\mathrm{pH} 7.5$, $5 \mathrm{mM}$ EDTA), and twice with PNK wash buffer (50 mM Tris at $\mathrm{pH} 7.4,10 \mathrm{mM} \mathrm{MgCl}_{2}, 0.5 \% \mathrm{NP}-40$ ). The second of each wash was rotated for 2-3 min at room temperature. Tags were dephosphorylated as described (Moore et al. 2014) and subjected to overnight $3^{\prime}$ ligation at $16^{\circ} \mathrm{C}$ with a preadenylated linker (Moore et al. 2018) with the following ligation reaction: $2 \mu \mathrm{L}$ of 25 uM linker, 2 $\mu \mathrm{L}$ of T4 RNA ligase 2, truncated K227Q (NEB), 1 $\times$ ligation buffer (supplied with ligase), $2 \mu \mathrm{L}$ of superasin RNase inhibitor (Promega), and $8 \mu \mathrm{L}$ of PEG8000 (supplied with ligase). The resulting beads were washed, ${ }^{32}$ P-labeled, and subjected to SDS-PAGE and transfered as described (Moore et al. 2014).

Tags were collected from nitrocellulose using phenol:chloroform:IAA (25:24:1 at $\mathrm{pH}$ 6.6) and tags were precipitated with a standard NaOAC precipitation. Cloning was performed using the BrdU-CLIP protocol as described (Moore et al. 2018) with a few exceptions. Briefly, the RT primer contained a 14-nt degenerate linker (a 3-nt degenerate sequence, a 4-nt multiplexing index, and a 7-nt unique molecular identifier), a 5 ' linker for PCR amplification, a spacer to prevent rolling circle amplification after circularization, and the reverse complementary sequence of the $3^{\prime}$ linker for reverse transcription. BrdUTP-labeled cDNA was specifically isolated via two sequential BrdUTP immunoprecipitations (with Abcam AB8955) and circularized with CircLigase II (Epicenter CL9025K). Ago-CLIP libraries were sequenced by MiSeq (Illumina) to obtain 75-nt single-end reads.

\section{CLIP data analysis (CTK)}

Sequencing files were demultiplexed (barcode.txt), linkers were trimmed, and reads were collapsed. Reads were aligned to $\mathrm{mm} 10$ genome assembly using Novoalign. All raw CLIP read processing and significant peak calling were performed using the CTK software package (Shah et al. 2017). CLIP peaks and CIMS analysis was carried out as previously described (Moore et al. 2014).

\section{CLIP data analysis (in $R$ )}

CLIP peak and unique tag output files were analyzed in $\mathrm{R}$ (Chan 2018) using Bioconductor (Gentleman et al. 2004).

\section{RNA sequencing}

For miRNA-seq, total RNA was extracted from fat pads of 13-wkold C57BL/6J male mice housed at room temperature and from inguinal fat pads of 13 -wk-old mice housed for 1 wk at $4^{\circ} \mathrm{C}$ prior to sacrifice. Following extraction, RNA was pooled into three groups of three mice for iWAT, eWAT, iBAT, aWAT, and cWAT fat (mWAT was not pooled). The TruSeq small RNA library preparation kit (Illumina) was used to prepare libraries for sequencing, which was performed by LC Sciences on an Illumina Hiseq platform.

For mRNA-seq, iBAT and eWAT tissue was dissected from 15wk-old C57BL/6J male mice and immediately flash-frozen in liquid nitrogen (dissected from the same cohort of mice used for HITS-CLIP). RNA was extracted and pooled into groups of two, a library was prepared using the Illumina TruSeq stranded total RNA library preparation kit, and sequencing was performed on an Illumina NextSeq 500.

\section{Primary adipocyte culture}

Primary adipocytes were isolated from 6-wk-old male C57BL/6J eWAT and iBAT adipose depots. Dissected adipose depots were incubated in $10 \mathrm{~mL}$ of digestion buffer for $16 \mathrm{~min}$ (eWAT) or 40 $\min (\mathrm{iBAT})$ in a $37^{\circ} \mathrm{C}$ shaking water bath $(140 \mathrm{rpm})$. iBAT digestion buffer was prepared as follows: $15 \mathrm{mg}$ of collagenase $\mathrm{B}$ (Roche 11088831001 ) was dissolved in $5 \mathrm{~mL}$ of $2 \times$ master mix consisting of $125 \mathrm{mM} \mathrm{NaCl}, 5 \mathrm{mM} \mathrm{KCl}, 1.3 \mathrm{mM} \mathrm{CaCl}_{2}, 5 \mathrm{mM}$ glucose, $1 \%$ penicillin-streptomycin, $4 \% \mathrm{BSA}$ in $\mathrm{H}_{2} \mathrm{O}$, and $5 \mathrm{~mL}$ of PBS. eWAT digestion buffer was prepared as follows: $100 \mathrm{mg}$ of collagenase $\mathrm{D}$ (Roche 11088882001) was dissolved in a solution of $10 \mathrm{~mL}$ of PBS, 
$200 \mu \mathrm{L}$ of $120 \mathrm{mg} / \mathrm{mL}$ dispase II (Roche 04942078001 ), and $40 \mu \mathrm{L}$ of $2.5 \mathrm{M} \mathrm{CaCl}_{2}$. Following digestion, the stromal vascular fraction was isolated by centrifugation and filtration at $100 \mu \mathrm{m}$ and 70 $\mu \mathrm{m}$, then plated in 12-well collagen-coated plates.

All primary adipocyte cultures were maintained at $37^{\circ} \mathrm{C}$ with $10 \% \mathrm{CO}_{2}$. Prior to differentiation, iBAT cells were cultured in GlutaMAX media (Gibco 10565) supplemented with $10 \%$ FBS and $1 \%$ penicillin-streptomycin and eWAT cells were cultured in ITS media (ITS media: $56.65 \% 1 \mathrm{~g} / \mathrm{L}$ glucose DMEM [Gibco11885-084], 37.65\% 1× MCDB210 at pH 7.25 [Sigma M6770], 2\% FBS, 2\% ITS premix [Corning 354352], 1\% $10 \mathrm{mM}$ L-ascorbic acid 2-phosphate in DMEM, 0.01\% $100 \mu \mathrm{g} / \mathrm{mL}$ bFGF BD Bio 13256-029], 0.5\% penicillin-streptomycin, $0.2 \%$ primocin). Following induction of differentiation, iBAT cells and eWAT cells were cultured in GlutaMAX media.

When iBAT preadipocytes reached $100 \%$ confluency and eWAT preadipocytes reached $95 \%$ confluency, differentiation was induced using a standard cocktail of $0.5 \mathrm{mM}$ IBMX, $1 \mathrm{mM}$ dexamethasone, $850 \mathrm{nM}$ insulin, and $1 \mathrm{mM}$ rosiglitazone dissolved in GlutaMAX media. After $48 \mathrm{~h}$, media was replaced with fresh media containing only $850 \mathrm{nM}$ insulin and $1 \mathrm{mM}$ rosiglitazone and after $96 \mathrm{~h}$ media was replaced with fresh media containing only insulin.

\section{Dual-luciferase assays}

5 '-phosphorylated oligonucleotides containing predicted binding sites of miR-29 target genes, 6 bp of flanking DNA, and SacI/XhoI restriction site overhands were annealed then ligated into the dual luciferase reporter plasmid (Promega E1960). For mutated sequences, three to four points were induced in the miR-29a seed binding site using the Q5 site-directed mutagenesis kit (NEB E0554S). Twenty nanograms of recombinant dual-luciferase plasmid and 6 pmol of either miR-29a mimic or scrambled control were mixed with $100 \mu \mathrm{L}$ of Opti-MEM containing $1 \mu \mathrm{L}$ of lipofectamine RNAiMax (Invitrogen 13778) in 24-well plates. Reverse transfection was initiated by adding 90,000 HEK-293A cells/ well in $500 \mu \mathrm{L}$. After $48 \mathrm{~h}$, firefly activity was measured by luminescence and normalized to Renilla activity.

\section{LNA and miRNA mimic transfections}

All cells were transfected on 12 -well plates $4 \mathrm{~d}$ after inducing differentiation. For each well, $3 \mu \mathrm{L}$ of $10 \mu \mathrm{M}$ double-stranded mature miRNA mimic (Dharmacon) or $20 \mu \mathrm{M}$ LNA (Qiagen) was mixed with $3 \mu \mathrm{L}$ of lipofectamine RNAiMAX in $100 \mu \mathrm{L}$ of Opti-MEM reduced serum media and added to cells following a 15-min incubation. RNA was collected in TRIzol (Invitrogen) $72 \mathrm{~h}$ after transfection.

RNA extraction, reverse transcriptase PCR, and quantitative PCR

RNA was extracted from tissues and cells using a TRIzol (Invitrogen)/chloroform extraction, followed by purification with RNeasy mini kits (Qiagen). To retain small RNAs during RNA purification, $1.5 \times$ volumes of $100 \%$ ethanol was used to precipitate RNA prior to column loading and RW1 buffer was substituted with RWT (Qiagen). For cDNA synthesis of mRNAs, the Applied Biosystems high-capacity cDNA synthesis kit was used with $1 \mu \mathrm{g}$ of purified RNA. For cDNA synthesis of miRNAs, reverse transcription using the universal primer $5^{\prime}$-CAGGTCC AGTTTTTTTTTTTTTTTVN-3' was used as previously reported (Balcells et al. 2011). qPCR for both mRNAs and miRNAs was performed on a QuantStudio 6 Flex machine (Applied Biosystems) using SYBR Green fluorescent dye (Applied Biosystems).
qPCR reactions were carried out in 384-well plates with a volume of $10 \mu \mathrm{L}$ containing $0.5 \mu \mathrm{M}$ forward and reverse primers, $1 \times \mathrm{qPCR}$ master mix, and 5 ng of mRNA-based cDNA or 1 ng of miRNAbased cDNA. MiRprimer2.0 was used to design primers for miRNA qPCR (Busk 2014).

\section{Leptin ELISA}

A mouse leptin ELISA kit (Crystal Chem 90030) was used to measure leptin concentrations in serum $(5 \mu \mathrm{L}$ per assay) or CM $(100 \mu \mathrm{L}$ per assay) according to the manufacturer's instructions.

Data availability

All raw data from HITS-CLIP and mRNA/miRNA sequencing are available through the Gene Expression Omnibus (GSE142677).

Notes on statistical analyses

All measurements and analyses were performed using distinct samples. All $t$-tests were two-tailed with an assumption of normality. Significance cutoffs for HITS-CLIP tag differential comparisons (tags per gene and tags per peak) were adjusted for multiple comparisons.

\section{Competing interest statement}

The authors declare no competing interests.

\section{Acknowledgments}

We thank C.H.J. Choi for providing samples from lean and obese mice, J. Chi for technical assistance with primary adipocyte cultures, T.S. Carroll for assistance with bioinformatics, and K. Hedbacker and J.M. Friedman for assistance with the leptin treatment experiment. This work was supported by The Rockefeller University Sackler Center for Biomedicine and Nutrition Research (S.O.), the American Diabetes Association Pathway to Stop Diabetes grant 1-17-ACE-17 (P.C.), National Institutes of Health (NIH) grant R01DK105965 (to P.S.), and NIH grant R35NS097404 (to R.B.D.). S.K.S. was supported by a Medical Scientist Training Program grant from the National Institute of General Medical Sciences of the NIH under award number T32GM007739 to the Weill Cornell/Rockefeller/Sloan Kettering Tri-Institutional MD-PhD Program.

Author contributions: S.O., E.A.M., and P.C. designed and planned the study, and R.B.D. and P.S. provided technical and conceptual input. E.A.M. and S.O. conducted benchwork for the HITS-CLIP experiments, and data analysis was performed by E.A.M. and M.K. S.O. and S.K.S. performed luciferase assays, primary cell gain- and loss-of-function experiments, and mouse studies. S.O., E.A.M., M.K., and F.M. performed bioinformatic analyses. The manuscript was written by S.O. and P.C. with contributions from all authors.

\section{References}

Acharya A, Berry DC, Zhang H, Jiang Y, Jones BT, Hammer RE, Graff JM, Mendell JT. 2019. miR-26 suppresses adipocyte progenitor differentiation and fat production by targeting Fbxl19. Genes Dev 33: 1367-1380. doi:10.1101/gad.328955.119 
Agarwal V, Bell GW, Nam JW, Bartel DP. 2015. Predicting effective microRNA target sites in mammalian mRNAs. Elife 4: e05005. doi:10.7554/eLife.05005

Balcells I, Cirera S, Busk PK. 2011. Specific and sensitive quantitative RT-PCR of miRNAs with DNA primers. BMC Biotechnol 11: 70. doi:10.1186/1472-6750-11-70

Busk PK. 2014. A tool for design of primers for microRNA-specific quantitative RT-qPCR. BMC Bioinformatics 15: 29. doi:10 $.1186 / 1471-2105-15-29$

Caravia XM, Fanjul V, Oliver E, Roiz-Valle D, Morán-Álvarez A, Desdin-Micó G, Mittelbrunn M, Cabo R, Vega JA, Rodríguez F, et al. 2018. The microRNA-29/PGCla regulatory axis is critical for metabolic control of cardiac function. PLOS Biol 16: e2006247. doi:10.1371/journal.pbio.2006247

Chan BKC. 2018. Data analysis using R programming. Adv Exp Med Biol 1082: 47-122. doi:10.1007/978-3-319-93791-5_2

Chen Y, Siegel F, Kipschull S, Haas B, Fröhlich H, Meister G, Pfeifer A. 2013. miR-155 regulates differentiation of brown and beige adipocytes via a bistable circuit. Nat Commun 4: 1769. doi:10.1038/ncomms2742

Chi SW, Zang JB, Mele A, Darnell RB. 2009. Argonaute HITSCLIP decodes microRNA-mRNA interaction maps. Nature 460: 479-486. doi:10.1038/nature08170

Cohen P, Levy JD, Zhang Y, Frontini A, Kolodin DP, Svensson KJ, Lo JC, Zeng X, Ye L, Khandekar MJ, et al. 2014. Ablation of PRDM16 and beige adipose causes metabolic dysfunction and a subcutaneous to visceral fat switch. Cell 156: 304316. doi:10.1016/j.cell.2013.12.021

Cypess AM, Lehman S, Williams G, Tal I, Rodman D, Goldfine AB, Kuo FC, Palmer EL, Tseng YH, Doria A, et al. 2009. Identification and importance of brown adipose tissue in adult humans. $N$ Engl I Med 360: 1509-1517. doi:10.1056/ NEJMoa0810780

Dallner OS, Marinis JM, Lu YH, Birsoy K, Werner E, Fayzikhodjaeva G, Dill BD, Molina H, Moscati A, Kutalik Z, et al. 2019. Dysregulation of a long noncoding RNA reduces leptin leading to a leptin-responsive form of obesity. Nat Med 25: 507-516. doi:10.1038/s41591-019-0370-1

Frederich RC, Hamann A, Anderson S, Löllmann B, Lowell BB, Flier JS. 1995. Leptin levels reflect body lipid content in mice: evidence for diet-induced resistance to leptin action. Nat Med 1: 1311-1314. doi:10.1038/nm1295-1311

Fu T, Seok S, Choi S, Huang Z, Suino-Powell K, Xu HE, Kemper B, Kemper JK. 2014. MicroRNA 34a inhibits beige and brown fat formation in obesity in part by suppressing adipocyte fibroblast growth factor 21 signaling and SIRT1 function. Mol Cell Biol 34: 4130-4142. doi:10.1128/MCB.00596-14

Gentleman RC, Carey VI, Bates DM, Bolstad B, Dettling M, Dudoit S, Ellis B, Gautier L, Ge Y, Gentry J, et al. 2004. Bioconductor: open software development for computational biology and bioinformatics. Genome Biol 5: R80. doi:10.1186/gb2004-5-10-r80

Giroud M, Karbiener M, Pisani DF, Ghandour RA, Beranger GE, Niemi T, Taittonen M, Nuutila P, Virtanen KA, Langin D, et al. 2016a. Let-7i-5p represses brite adipocyte function in mice and humans. Sci Rep 6: 28613. doi:10.1038/srep28613

Giroud M, Pisani DF, Karbiener M, Barquissau V, Ghandour RA, Tews D, Fischer-Posovszky P, Chambard JC, Knippschild U, Niemi T, et al. 2016b. miR-125b affects mitochondrial biogenesis and impairs brite adipocyte formation and function. Mol Metab 5: 615-625. doi:10.1016/j.molmet.2016.06.005

Glantschnig C, Koenen M, Gil-Lozano M, Karbiener M, Pickrahn I, Williams-Dautovich J, Patel R, Cummins CL, Giroud M, Hartleben G, et al. 2019. A miR-29a-driven negative feedback loop regulates peripheral glucocorticoid receptor signaling. FASEB J 33: 5924-5941. doi:10.1096/fj.201801385RR

Hardy OT, Czech MP, Corvera S. 2012. What causes the insulin resistance underlying obesity? Curr Opin Endocrinol Diabetes Obes 19: 81-87. doi:10.1097/MED.0b013e3283514e13

Hu F, Wang M, Xiao T, Yin B, He L, Meng W, Dong M, Liu F. 2015. miR-30 promotes thermogenesis and the development of beige fat by targeting RIP140. Diabetes 64: 2056-2068. doi:10.2337/db14-1117

Jayedi A, Soltani S, Zargar MS, Khan TA, Shab-Bidar S. 2020. Central fatness and risk of all cause mortality: systematic review and dose-response meta-analysis of 72 prospective cohort studies. BM/ 370: m3324. doi:10.1136/bmj.m3324

Kajimura S, Spiegelman BM, Seale P. 2015. Brown and beige fat: physiological roles beyond heat generation. Cell Metab 22: 546-559. doi:10.1016/j.cmet.2015.09.007

Koh EH, Chernis N, Saha PK, Xiao L, Bader DA, Zhu B, Rajapakshe K, Hamilton MP, Liu X, Perera D, et al. 2018. miR30a remodels subcutaneous adipose tissue inflammation to improve insulin sensitivity in obesity. Diabetes 67: 25412553. doi:10.2337/db17-1378

Kristensen MM, Davidsen PK, Vigelsø A, Hansen CN, Jensen LJ, Jessen N, Bruun JM, Dela F, Helge JW. 2017. miRNAs in human subcutaneous adipose tissue: effects of weight loss induced by hypocaloric diet and exercise. Obesity (Silver Spring) 25: 572-580. doi:10.1002/oby.21765

Kurtz CL, Fannin EE, Toth CL, Pearson DS, Vickers KC, Sethupathy P. 2015. Inhibition of miR-29 has a significant lipid-lowering benefit through suppression of lipogenic programs in liver. Sci Rep 5: 12911. doi:10.1038/srep12911

Lo KA, Huang S, Walet ACE, Zhang ZC, Leow MK, Liu M, Sun L. 2018. Adipocyte long-noncoding RNA transcriptome analysis of obese mice identified Lnc-Leptin, which regulates Leptin. Diabetes 67: 1045-1056. doi:10.2337/db17-0526

Luna JM, Barajas JM, Teng KY, Sun HL, Moore MJ, Rice CM, Darnell RB, Ghoshal K. 2017. Argonaute CLIP defines a deregulated miR-122-bound transcriptome that correlates with patient survival in human liver cancer. Mol Cell 67: 400-410.e7. doi:10.1016/j.molcel.2017.06.025

Maffei M, Halaas J, Ravussin E, Pratley RE, Lee GH, Zhang Y, Fei H, Kim S, Lallone R, Ranganathan S, et al. 1995. Leptin levels in human and rodent: measurement of plasma leptin and ob RNA in obese and weight-reduced subjects. Nat Med 1: 1155-1161. doi:10.1038/nm1195-1155

Moore MJ, Zhang C, Gantman EC, Mele A, Darnell JC, Darnell RB. 2014. Mapping Argonaute and conventional RNA-binding protein interactions with RNA at single-nucleotide resolution using HITS-CLIP and CIMS analysis. Nat Protoc 9: 263-293. doi:10.1038/nprot.2014.012

Moore MJ, Blachere NE, Fak JJ, Park CY, Sawicka K, Parveen S, Zucker-Scharff I, Moltedo B, Rudensky AY, Darnell RB. 2018. ZFP36 RNA-binding proteins restrain $\mathrm{T}$ cell activation and anti-viral immunity. Elife 7: e33057. doi:10.7554/eLife .33057

Mori M, Nakagami H, Rodriguez-Araujo G, Nimura K, Kaneda Y. 2012. Essential role for miR-196a in brown adipogenesis of white fat progenitor cells. PLOS Biol 10: e1001314. doi:10 .1371/journal.pbio.1001314

Mori MA, Thomou T, Boucher J, Lee KY, Lallukka S, Kim JK, Torriani $\mathrm{M}$, Yki-Järvinen $\mathrm{H}$, Grinspoon SK, Cypess AM, et al. 2014. Altered miRNA processing disrupts brown/white adipocyte determination and associates with lipodystrophy. J Clin Invest 124: 3339-3351. doi:10.1172/JCI73468

Neeland IJ, Ross R, Després JP, Matsuzawa Y, Yamashita S, Shai I, Seidell J, Magni P, Santos RD, Arsenault B, et al. 2019. Visceral 
and ectopic fat, atherosclerosis, and cardiometabolic disease: a position statement. Lancet Diabetes Endocrinol 7: 715-725. doi:10.1016/S2213-8587/19|30084-1

Pullen TJ, da Silva Xavier G, Kelsey G, Rutter GA. 2011. miR-29a and miR-29b contribute to pancreatic $\beta$-cell-specific silencing of monocarboxylate transporter 1 (Mct1). Mol Cell Biol 31: 3182-3194. doi:10.1128/MCB.01433-10

Reis FC, Branquinho JL, Brandao BB, Guerra BA, Silva ID, Frontini A, Thomou T, Sartini L, Cinti S, Kahn CR, et al. 2016. Fat-specific Dicer deficiency accelerates aging and mitigates several effects of dietary restriction in mice. Aging 8: 1201-1222.

Rosen ED, Spiegelman BM. 2014. What we talk about when we talk about fat. Cell 156: 20-44. doi:10.1016/j.cell.2013.12.012

Rosenwald M, Perdikari A, Rülicke T, Wolfrum C. 2013. Bi-directional interconversion of brite and white adipocytes. Nat Cell Biol 15: 659-667. doi:10.1038/ncb2740

Sawicka K, Hale CR, Park CY, Fak JJ, Gresack JE, Van Driesche SJ, Kang JJ, Darnell JC, Darnell RB. 2019. FMRP has a cell-typespecific role in CA1 pyramidal neurons to regulate autism-related transcripts and circadian memory. Elife 8: e46919. doi:10 .7554/eLife.46919

Seale P, Kajimura S, Yang W, Chin S, Rohas LM, Uldry M, Tavernier G, Langin D, Spiegelman BM. 2007. Transcriptional control of brown fat determination by PRDM16. Cell Metab 6: 38-54. doi:10.1016/j.cmet.2007.06.001

Shah A, Qian Y, Weyn-Vanhentenryck SM, Zhang C. 2017. CLIP tool Kit (CTK): a flexible and robust pipeline to analyze CLIP sequencing data. Bioinformatics 33: 566-567.

Spengler RM, Zhang X, Cheng C, McLendon JM, Skeie JM, Johnson FL, Davidson BL, Boudreau RL. 2016. Elucidation of transcriptome-wide microRNA binding sites in human cardiac tissues by Ago2 HITS-CLIP. Nucleic Acids Res 44: 7120-7131.

Stanford KI, Middelbeek RJ, Townsend KL, An D, Nygaard EB, Hitchcox KM, Markan KR, Nakano K, Hirshman MF, Tseng $\mathrm{YH}$, et al. 2013. Brown adipose tissue regulates glucose homeostasis and insulin sensitivity. I Clin Invest 123: 215223. doi:10.1172/JCI62308

Sun L, Trajkovski M. 2014. MiR-27 orchestrates the transcriptional regulation of brown adipogenesis. Metab Clin Exp 63: 272-282. doi:10.1016/j.metabol.2013.10.004

Sun L, Xie H, Mori MA, Alexander R, Yuan B, Hattangadi SM, Liu Q, Kahn CR, Lodish HF. 2011. Mir193b-365 is essential for brown fat differentiation. Nat Cell Biol 13: 958-965. doi:10 $.1038 / \mathrm{ncb} 2286$

Tontonoz P, Spiegelman BM. 2008. Fat and beyond: the diverse biology of PPAR y. Annu Rev Biochem 77: 289-312. doi:10 .1146/annurev.biochem.77.061307.091829

Tontonoz P, Hu E, Spiegelman BM. 1994. Stimulation of adipogenesis in fibroblasts by PPAR $\gamma 2$, a lipid-activated transcription factor. Cell 79: 1147-1156. doi:10.1016/0092-8674(94) 90006-X

Trajkovski M, Hausser J, Soutschek J, Bhat B, Akin A, Zavolan M, Heim MH, Stoffel M. 2011. MicroRNAs 103 and 107 regulate insulin sensitivity. Nature 474: 649-653. doi:10.1038/ nature 10112

Trajkovski M, Ahmed K, Esau CC, Stoffel M. 2012. MyomiR-133 regulates brown fat differentiation through Prdm16. Nat Cell Biol 14: $1330-1335$. doi: $10.1038 /$ ncb2612

van Marken Lichtenbelt WD, Vanhommerig JW, Smulders NM, Drossaerts JM, Kemerink GJ, Bouvy ND, Schrauwen P, Teule GJ. 2009. Cold-activated brown adipose tissue in healthy men. N Engl J Med 360: 1500-1508. doi:10.1056/NEJMoa0808718

Ventayol M, Viñas JL, Sola A, Jung M, Brüne B, Pi F, Mastora C, Hotter G. 2014. miRNA let-7e targeting MMP9 is involved in adipose-derived stem cell differentiation toward epithelia. Cell Death Dis 5: e1048. doi:10.1038/cddis.2014.2

Virtanen KA, Lidell ME, Orava J, Heglind M, Westergren R, Niemi T, Taittonen M, Laine J, Savisto NJ, Enerbäck S, et al. 2009. Functional brown adipose tissue in healthy adults. $N$ Engl J Med 360: 1518-1525. doi:10.1056/NEJMoa0808949

Ward ZJ, Bleich SN, Cradock AL, Barrett JL, Giles CM, Flax C, Long MW, Gortmaker SL. 2019. Projected U.S. state-level prevalence of adult obesity and severe obesity. $N$ Engl J Med 381: 2440-2450. doi:10.1056/NEJMsa1909301

Wu J, Boström P, Sparks LM, Ye L, Choi JH, Giang AH, Khandekar M, Virtanen KA, Nuutila P, Schaart G, et al. 2012. Beige adipocytes are a distinct type of thermogenic fat cell in mouse and human. Cell 150: 366-376. doi:10.1016/j.cell.2012.05.016

Zhang XM, Wang LH, Su DJ, Zhu D, Li QM, Chi MH. 2016. MicroRNA-29b promotes the adipogenic differentiation of human adipose tissue-derived stromal cells. Obesity (Silver Spring) 24: 1097-1105. doi:10.1002/oby.21467 


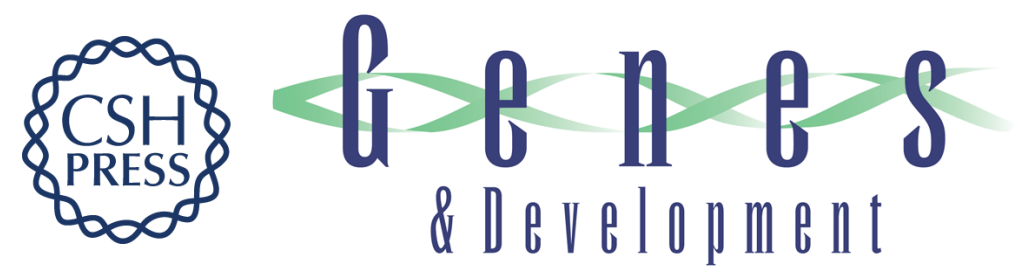

\section{AGO HITS-CLIP reveals distinct miRNA regulation of white and brown adipose tissue identity}

Sean O'Connor, Elisabeth A. Murphy, Sarah K. Szwed, et al.

Genes Dev. 2021, 35: originally published online April 8, 2021

Access the most recent version at doi:10.1101/gad.345447.120

\section{Supplemental http://genesdev.cshlp.org/content/suppl/2021/04/07/gad.345447.120.DC1 Material}

References This article cites 53 articles, 7 of which can be accessed free at: http://genesdev.cshlp.org/content/35/9-10/771.full.html\#ref-list-1

Creative This article is distributed exclusively by Cold Spring Harbor Laboratory Press for the first Commons six months after the full-issue publication date (see

License http://genesdev.cshlp.org/site/misc/terms.xhtml). After six months, it is available under a Creative Commons License (Attribution-NonCommercial 4.0 International), as described at http://creativecommons.org/licenses/by-nc/4.0/.

Email Alerting Receive free email alerts when new articles cite this article - sign up in the box at the top Service right corner of the article or click here.

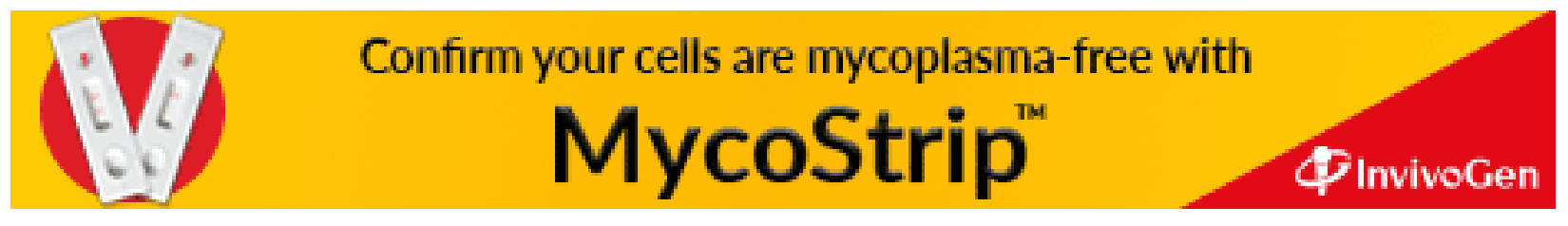

